\title{
A produção de sentidos num contexto de aproximação entre arte e vida
}

The production of meanings in context approach between art and life

Luzia Renata da Silvai

Universidade do Estado de Santa Catarina

\section{Resumo}

O desenvolvimento desse texto se constitui a partir da necessidade de pensar a prática artística em relação com propostas pedagógicas transformadoras. A partir desse interesse, problematiza-se alguns artistas que transformaram seus campos, contextos e formas de atuação por não filiarem-se a ideia de arte tradicionalmente aceita. Por consequência, a reflexão formulada reflete sobre a importância que o educador Rudolf Steiner teve na constituição e na visão de arte de Joseph Beuys e os possíveis desdobramentos do pensamento desse artista na atuação do professor artista José Luiz Kinceler que, na lida com a arte, propôs ações transformadoras em um contexto de ensino de arte.

Palavras chaves: Produção de sentido, arte, educação.

\begin{abstract}
The development of this text comes from the need of thinking of the artistic practice in relation to transformative educational proposals. With this objective, a few artists who did not comply with the idea of traditional art and transformed their fields, contexts and forms of action are analyzed. Consequently, the reflection formulated reflects on the importance that educator Rudolf Steiner had in the constitution and art vision of Joseph Beuys, and the possible impact of Steiner's way of the thinking in the performance of art professor José Luiz Kinceler, that in dealing with art, proposed transformative actions in the context of Art education.
\end{abstract}

Key words: sense of production, art, education.

Revista Digital do LAV - Santa Maria - vol. 9, n. 3, p. 104 - 118 - set./dez. 2016 ISSN 1983 - 7348 http://dx.doi.org/10.5902/1983734824339 


\section{Influências da filosofia antroposófica na obra de Joseph Beuys ${ }^{1}$}

Da educação das crianças deveriam se ocupar os artistas, colecionadores e mágicos.

Walter Benjamin

Esta frase de Benjamin renova o espírito didático do artista que encontra no ensino uma extensão de sua prática, no entanto, os interesses políticos, econômicos e sociais, bem como a observação dos acontecimentos históricos, podem revelar a dimensão romântica deste fragmento $^{2}$, pois o mesmo Benjamin, anos depois de tê-lo escrito, foi vítima de um sistema no qual a arte aliada a outras ferramentas, foi usada pedagogicamente para a afirmação do ideal nazista.

Em geral, nos regimes totalitários ocidentais, temos visto que a política tem se apropriado da retórica das artes para alcançar uma transformação cultural aliada ao domínio territorial e ideológico, o filme "O Triunfo da Vontade" (1935) de Leni Riefenstahl (figura 1) é um exemplo de como o cinema inspirou-se na estética clássica para fundamentar os ideais do Nacional Socialismo com reconhecido rigor estético e o domínio técnico. No documentário "Leni Riefenstahl - A Deusa Imperfeita" (1993) a cineasta alega que era apenas uma artista a serviço de sua arte, no entanto, o reconhecimento incontestável de seu talento não a livrou do ostracismo após o fim da $2^{a}$ Guerra Mundial.

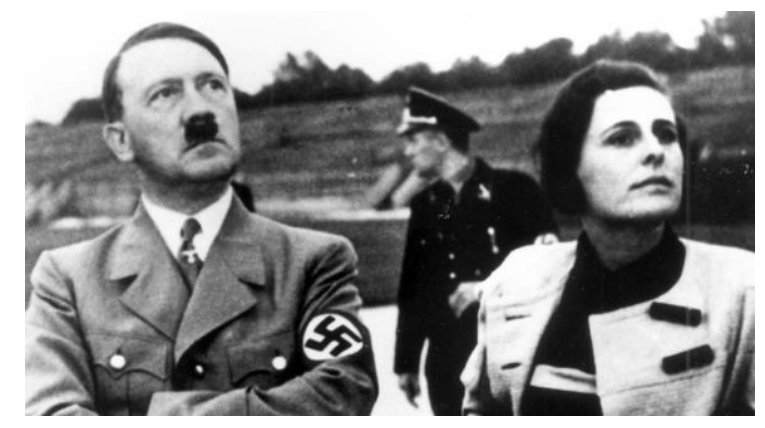

Figura 1: Hitler e Riefenstahl durante as fimagens de Trinfo da Vontade, Alemanha, 1934. Fonte: http://www.revistadehistoria.com.br/secao/cine-historia/sonho-e-trauma

Nas artes visuais, o poeta modernista Marinetti declara sua simpatia ao fascismo quando escreve: "Queremos glorificar a guerra - a única higiene do mundo -, o militarismo,

\footnotetext{
${ }^{1}$ Há um universo de possibilidades a serem exploradas nessa linha, no entanto, o texto trata de apenas alguns aspectos devido ao desenvolvimento da proposta do artigo.

${ }^{2}$ Walter Benjamin, 2005.
}

Revista Digital do LAV - Santa Maria - vol. 9, n. 3, p. 104 - 118 - set./dez. 2016 ISSN 1983 - 7348 http://dx.doi.org/10.5902/1983734824339 
o patriotismo, o ato destrutivo dos anarquistas, as belas ideias pelas quais um indivíduo morre, o desprezo pelas mulheres" (LYNTON, 2000, p. 71).

Os exemplos citados apenas indicam que o simples fato de ter artistas, poetas, cineastas ou mágicos responsáveis pela educação das crianças não está de modo algum relacionado a uma educação "salvadora", pois tanto a arte quanto à pedagogia são ações políticas que muitas vezes atendem a interesses obscuros.

A fim de ponderar sobre a questão do artista que entende sua arte como uma forma de ação política, o texto entrelaça a obra Joseph Beuys, para quem a arte deveria desempenhar um papel ativo na sociedade (2001), com a pedagogia antroposófica de Rudolf Steiner, onde qualquer método de ensino deve ser mergulhado no artístico (2003). Ambos, cada um a seu modo, pretendiam aproximar o homem da natureza e das coisas primordiais misturando a arte na vida.

A trajetória de Beuys acumula experiências incomuns para um artista. Durante a Segunda Guerra Mundial ele serviu à Força Aérea Alemã pilotando um avião Stuka, em um desses voos ele viria a cair dos céus após ser atingido na região da Criméia, sendo acolhido por povos Tártaros que cuidaram de suas feridas com com ervas recobertas por feltro e gordura, (BORER, 2001) talvez seu interesse pela natureza e pela transformação das substâncias venha desse segundo nascimento.

Certas tensões rondam sua biografia. Envolto em um mito criado por ele mesmo, temos visto que tanto sua obra quanto sua biografia são suscetíveis à dúvidas e desconfianças que sugerem a comprovação de sua lenda.

No entanto, uma lenda nunca pode ser verificável. No sentido da palavra, lenda é aquilo que deve ser lido e dito, aquilo que é narrado com status de verdade. Beuys criou um mito e esse mito é um elemento integrante de seu projeto artístico. No livro de Alain Borer lemos:

Ainda jovem, começou o estudo de medicina, pretendendo devotar-se aos mais humildes, esse desejo, no entanto, foi destruído quando pilotava o seu Stuka, depois de ingressar na Luftwalle em 1941. No ano de 1944, aos 22 anos, ele miraculosamente escapou da morte na Ásia. O seu avião, um JU 87, caiu numa região coberta de neve chamada Crime ou Crimeia. Joseph ficou inconsciente por vários dias, semicongelado, foi levado por genuínos Tártaros, que cuidaram de suas chagas. O povo, natural do lugar, logo o tomou por um dos seus: "Du nix Njemcky, du Tatar", e trouxe-o de volta à vida, enrolando-o em seus tradicionais cobertores de feltro e aquecendo-o com gordura animal. (BORER, 2001, p. 13)

A lenda criada por Beuys recria sua própria existência, alimenta sua obra e é alimentada por ela. Por meio da lenda, podemos nos aproximar dos desejos, dos medos e 
anseios humanos tendo como guia nosso imaginário. Nesse lugar, as narrativas imagéticas transmitidas por aqueles que viviam mais conectados com natureza tem a função de ajudar as pessoas a assimilarem e dissiparem os sentimentos aflitivos. E isso é feito através de uma oralidade, tal qual indicou Benjamin (2012) no texto "Pobreza e experiência" - da boca para ouvido - vivendo uma experiência ancestral.

Para Benjamin a experiência estava em declínio, pois esta teria que passar pelo acúmulo das histórias e saberes transmitidos no boca-a-boca. No entanto, essa oralidade demasiadamente arraigada ao passado e a rememoração não mais existia, pois as histórias passaram a ser escritas e massivamente distribuídas em um material impresso para uma população que não teve a vivência. Portanto, é uma noção de experiência ligada a memória. Apenas traçando um paralelo com a antroposofia, a respeito da decadência da experiência humana Steiner diz:

As palavras devem significar o que realmente existe. E, com efeito, neste caso havia antigamente uma espécie de ciência que se ligava diretamente à prática. [...] Naquele tempo uma pessoa contava à outra aquilo que sabia, em consequência das suas próprias experiências, e pressentia-se desde logo se alguém era fanfarrão, ou se realmente tinha acumulado experiências, pois estas coisas são completamente diferentes, quando se ouve alguém conversando. [...] Porquanto a tinta preta do impressor tem sido frequentemente acrescentada às demais coisas, como se fosse uma nova autoridade. (STEINER, 2005, p.73)

Ao potencializar o ato da narrativa através de um conto ou de uma lenda, Steiner (2003) confirma o poder que essa oralidade tem de atingir a pessoa como um todo, em seu corpo físico e em seu corpo astral ${ }^{3}$.

Nessa mesma vibração, ao prospectar uma conexão entre dois mundos Beuys (figura 3) realiza o trabalho "Como se explicam quadros a uma lebre morta" nessa ação, o artista usa sapatos com sola de feltro e cobre, tem o rosto envolto em mel e ouro em pó, performativamente ele ocupa o espaço expositivo embalando no colo uma lebre morta, nesse embalo ele murmura palavras em uma língua obscura relacionando os reinos animais, vegetais, minerais conferindo-Ihes alto teor simbólico. "A imagem solitária do homem que tenta se comunicar de forma ritualizada com um animal já morto sintetiza um interesse

\footnotetext{
${ }^{3}$ Benjamin não se referia ao corpo astral, mas sim a rememoração possível através da oralidade, da figura do narrador que para ele, na década de 1930 já não existia mais.
}

Revista Digital do LAV - Santa Maria - vol. 9, n. 3, p. 104 - 118 - set./dez. 2016 ISSN 1983 - 7348 http://dx.doi.org/10.5902/1983734824339 
declarado do artista por uma revisitação de um saber primitivo e por uma igualdade no diálogo entre homem e animal" (MARCONDES, 2015).

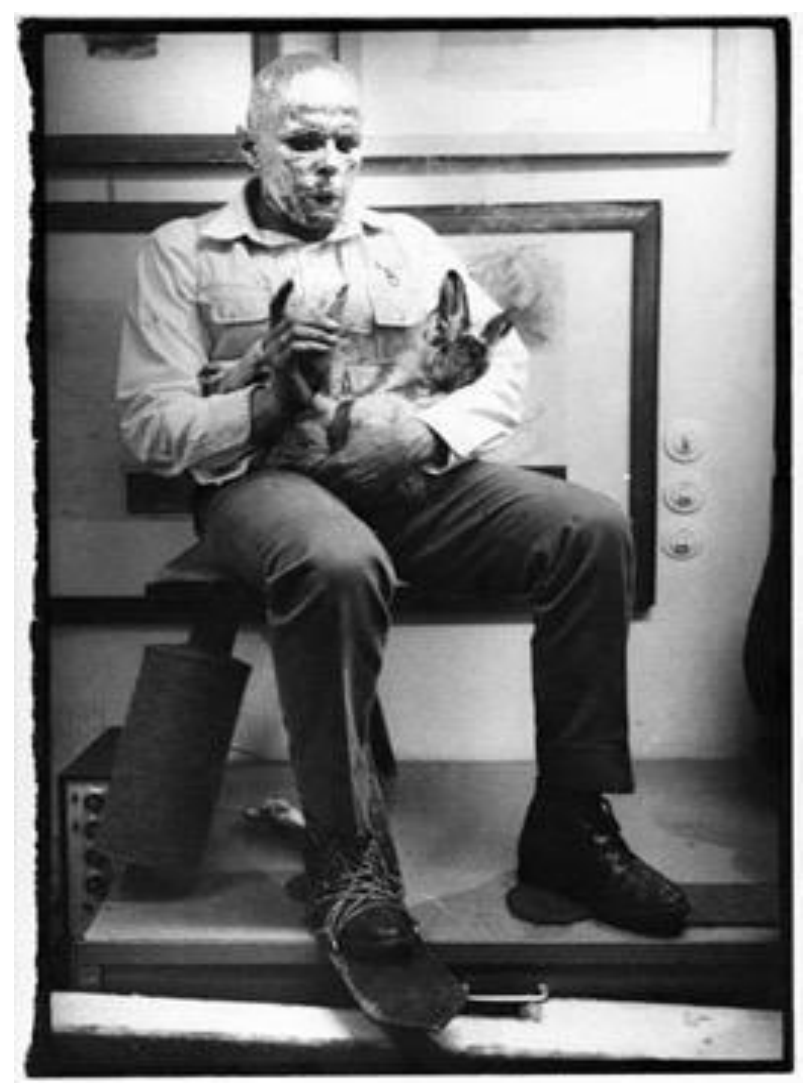

Figura 2: Joseph Beuys, Como explicar pintura a uma lebre morta, 1965.

Fonte:http://www.artecapital.net/perspetiva-149-artecapital-foco-em-madrid-arcoe-12-exposicoes-para-visitar

Muito já foi escrito sobre a jornada de Beuys e o caráter mitológico que atravessa seu trabalho. Essa característica marcante encontra em Joseph Campbell (1991) suporte para a compreensão de um Beuys que buscava, como um herói, redimir-se e redimir a sociedade que se encontrava doente por estar afastada na natureza.

Nesse contexto, o artista criou uma obra cuja variedade de materiais ligam-se a uma proposta de unir arte e vida alterando a estrutura social e política. Ou seja, a arte para ele pode ser usada como um meio para transformar a sociedade, e o oficio da pedagogia poderia proporcionar essa transformação. Nesta tarefa, o artista inspira-se no educador Rudolf Steiner 
para forjar sua obra.

\section{Entrelaçamentos feltrados entre Beuys e Rudolf Steiner}

Rudolf Steiner (1861-1925) pedagogo austríaco criador da Antroposofia, do grego "conhecimento do ser humano", método que, desde os primórdios, tem atuado em várias áreas do conhecimento buscando com isso aproximar o ser humano da natureza e do universo.

Com intuito de atuar no ser desde a sua formação, Steiner criou em 1919, em Stuttgart, Alemanha, a primeira escola antroposófica inicialmente para os filhos dos operários da fábrica de cigarros Waldorf-Astória, de modo que o nome da metodologia carrega o nome da fábrica de cigarros sede da primeira escola. Atualmente existem escolas Waldorf espalhadas por todo o mundo e a metodologia ampliou-se para o tratamento do ser como um todo.

Nossa pretensão neste artigo não visa o aprofundamento da metodologia antroposófica, tampouco a explicação da obra de Beuys, mas encontrar alguns pontos de contato entre um conceito de arte ampliada e um conceito de educação ampliada para pensar nos desdobramentos que essas visões de mundo tiveram na constituição de uma vertente da arte contemporânea.

Situando moderadamente a antroposofia, uma das maneiras de pensar o homem é relacionando-a com a natureza à sua volta, de modo que ele é visto como um ser que comunga semelhanças com os reinos mineral, vegetal e animal mas, por ter consciência, diferencia-se desses. Essa característica é presente em quase toda a trajetória de Beuys.

Uma das formas de pensar o ser é através da "Quadrimembração". Visando uma aproximação com a palavra lembramos que trata-se dos quatro elementos constituintes do ser humano: corpo físico, do corpo etérico, do corpo astral (alma) e do Eu (espírito).

Corpo físico: é a estrutura sólida, material, palpável e mensurável, sujeita às leis da física e da química. É o corpo que compartilhamos com os minerais. É uma estrutura totalmente inerte e morta quando não permeada pelo segundo elemento (corpo etérico). Corpo Etérico ou Vital: são as forças responsáveis por todo o princípio da vida, seja nos vegetais, animais ou seres humanos. O corpo vital nos dá a possibilidade de desenvolvermos vida vegetativa: crescimento, regeneração e reprodução. Corpo Astral (corpo anímico ou alma): são as forças da consciência, presentes nos reinos animal e humano, e que

Revista Digital do LAV - Santa Maria - vol. 9, n. 3, p. 104 - 118 - set./dez. 2016 ISSN 1983 - 7348 http://dx.doi.org/10.5902/1983734824339 
formam o fundamento para uma vida sensitiva. Tem um papel de "organizador" dos processos vitais e, de maneira didática, podemos dizer que ele manifesta-se como sistema nervoso e vida psíquica. Organização do Eu (espírito): é o elemento característico do ser humano, que o distingue dos demais reinos e seres da natureza. É o responsável pela atuação saudável dos demais corpos e o aparecimento do andar ereto, da fala e do pensar. É a nossa individualidade, nossa entidade espiritual. Relaciona-se com os processos de calor no âmbito do organismo. (ABMA, 2015).

A antroposofia é atravessada por essa espiritualidade, isso leva Steiner a romper com o ensino tradicional para construir uma nova edificação fundamentada na harmonia entre o "ser humano superior, o ser humano anímico-espiritual, e o ser humano físico corpóreo, o ser humano inferior" (2003 p.11).

De modo que as matérias obrigatórias e convencionais são, a partir de então, conectadas com a natureza do ser humano e as imagens que o cercam. Para o educador, "Todo e qualquer método deve ser mergulhado no artístico" (2003, p. 14). De modo que na alfabetização o ensino das letras deveria passar primeiramente pela imagem, passando pelas mãos e pelos sentidos do corpo antes mesmo de passar pelo intelecto.

Se pensarmos nas esculturas, ou mesmo nas ações artísticas desenvolvidas por Beuys, podemos supor que, o que está impregnado ali são as formas cruas, a busca pela substância da matéria, o contato com o primordial, sem uma antecipação de um conceito. Muito embora para aproximarmo-nos de sua obra, como de qualquer obra complexa, somos imediatamente acionados intelectualmente para buscar nossas referências, porque assim fomos acostumados a fazer.

Essa conceituação evidencia-se sobremaneira quando nos damos conta de que na obra de Beuys a estética desaparece. A orientação vai em outra direção e, com certeza, essa direção não é a do belo, mas a da transformação da sociedade pela arte. E essa transformação ele conduz como um pedagogo/pastor/artista engajado em uma mudança estrutural na sociedade através de sua fala.

No entanto, penso na sensação que tenho ao escrever sobre uma ação que nunca presenciei. Li sobre Beuys, vi suas obras em livros, assisti a entrevistas e vídeos de suas ações, mas a experiência de sua obra, para mim, é mediada por fotografias, vídeos e textos. Aqui, novamente Walter Benjamin no texto já citado, reforça a mediação pela qual esse artigo é escrito. Lembrando que essa é uma prática habitual na academia.

Meu conhecimento da obra de Beuys e da pedagogia de Steiner não são semelhantes, a de Beuys passa pela leitura acadêmica, a de Steiner, pela vivência na escola 
Waldorf Anabá, em Florianópolis. A experiência de participar de uma escola que propõe uma metodologia ampliada contribui para a compreensão da obra de um dos artistas mais paradigmáticos do nosso tempo.

A costura entre uma pedagogia antroposófica e uma arte antropológica ${ }^{4}$ cria um ponto cruz no conceito de Estrutura Social, na qual, a pesquisadora Magda Vicini ${ }^{5}$ reflete sobre a obra do artista entrelaçada/feltrada com os ensinamentos de Steiner. Sabemos que a cera de abelha é um dos materiais que fazem parte do inventário do artista, seu interesse pela transformação da matéria e pela substância são constantemente retomados a partir de inúmeros trabalhos.

Para a pesquisadora o interesse de Beuys pela cera pode ter surgido após sua leitura do livro "Abelhas", de Steiner. Numa das frases do livro, o autor diz que "[...] a vida da colmeia repousa no fato de que as abelhas colaboram entre si de um modo muito preciso, muito mais que as vespas e as formigas, e de que as abelhas realizam o trabalho de tal maneira que tudo se harmonize" (STEINER, 2005, p. 28).

Além do espaço colaborativo na colmeia, residem nessa organização aspectos materiais que remetem aos problemas físicos da escultura. O calor interno da colônia ajuda as abelhas a transformarem fluídos líquidos em escultura cristalizada, essa observação ajudou-o a pensar na metamorfose da gordura ao alterar seu estado físico (VICINI, 2011).

Beuys estava interessado na anterioridade da matéria pois como artista/professor/condutor, entender os processos é fundamental.

Analisando a materialidade de sua obra, vemos que Beuys convoca o outro rumo a uma aproximação com a natureza das coisas, e essa convocação é primordial na pedagogia Waldorf, onde a pessoa é levada a realizar os processos da vida perpassando sua trajetória pelo começo, meio e fim.

Para ambos, nos diferentes contextos, a sociedade encontrava-se doente devido ao afastamento da natureza. De modo que a arte, a medicina e a educação poderiam unir novamente as coisas que foram separadas pelo excesso de cientificismo e convenções inventadas.

Nesse aspecto, pondera-se o fato de que a noção de arte que temos atualmente é baseada em uma convenção, em um acordo entre pessoas, e nesse acordo as partes consideraram por bem que a obra de arte deveria ser uma coisa separada da vida.

Não foi sempre assim, e não é assim em todas as esferas sociais e culturais, no entanto, quando se fala na " grande arte" entende-se que houve um momento em ela saiu do cotidiano e passou a ter um lugar para admiração e legitimação, e nesse momento ela

\footnotetext{
${ }^{4}$ Por vezes, uma proposta de arte carregada de cunho antropológico, pode apresentar sinais de estereótipos.

${ }^{5}$ A tese de doutorado e a dissertação de mestrado da pesquisadora Magda Vincini foi sobre a obra de Joseph Beuys. De sua dissertação foi publicado o livro: Arte de Joseph Beuys: pedagogia e hipermídia.
}

Revista Digital do LAV - Santa Maria - vol. 9, n. 3, p. 104 - 118 - set./dez. 2016 ISSN 1983 - 7348 http://dx.doi.org/10.5902/1983734824339 
distanciou-se das outras coisas do mundo. Condição que leva alguns artistas contemporâneos a tentar unir o que foi separado por estas convenções.

\section{Desdobramentos na arte contemporânea}

O desenvolvimento desse texto teve como ponto de partida perceber algumas das influencias que Beuys possa ter tido de Rudolf Steiner. Essa preocupação não recai sobre a necessidade de determinar uma origem da produção do artista, ou um motivo que o levou a trabalhar por uma arte ampliada, e sim, encontrar confluências entre uma proposta de arte transformadora e uma proposta de educação transformadora.

A partir desse encontro, nossa atenção volta-se para os desdobramentos desses pensamentos na produção de uma vertente da arte contemporânea que tem como objetivo diluir a arte na vida valorizando ações colaborativas, dos saberes e fazeres que escapam do metier artístico fundamentado pelas convenções traçadas para a arte tradicional. Em tais convenções, os objetos artísticos eram destinados a um determinado lugar de culto, pertenciam a um determinado sistema de legitimação, escrita e circulação que, segundo Dewey, empobreciam a experiência: "Quando um produto artístico atinge status de clássico, de algum modo, ele se isola das condições humanas em que foi criado e das consequências humanas que gera na experiência real de vida" (DEWEY, p.59, 2010).

Dewey pode estar sugerindo que o isolamento dos objetos artísticos interferem na recepção e assim, na experiência da arte. Celso Favaretto ${ }^{6}$ comenta que para Dewey "[...] a experiência diz respeito exatamente ao estar em relação com as pessoas e as coisas, sistematicamente organizadas de uma maneira ou de outra, em funcionamento e produzindo efeitos. Efeitos esperados e efeitos que não são esperados [...].

Diante desta consideração, é interessante pensar nos processos artísticos que atuam diretamente no espaço aberto do cotidiano, de certo modo forjando uma experiência na vida através de ações artísticas colaborativas que provocam descontinuidades.

Para entender a noção de descontinuidade em arte devemos considerar o fato de que recebemos uma cultura em movimento, que cabe a nós, em nossa presente condição vivenciar, e, deste espaço tempo, articular conjuntamente a nossos desejos e percepções outras possibilidades de habitar este mundo que agora nos toca praticar. Em definitiva de instalar um outro imaginário a partir de práticas artísticas, pautadas em desconstruir o que tenta se manter reificado por agendas de saber

\footnotetext{
${ }^{6}$ Video: John Dewey I: A Relevância da Experiência (1/2).
}

Revista Digital do LAV - Santa Maria - vol. 9, n. 3, p. 104 - 118 - set./dez. 2016 ISSN 1983 - 7348 http://dx.doi.org/10.5902/1983734824339 
e poder que se instalam na convencionalidade (KINCELER, p. 1791, 2008).

No rastro da obra de Beuys, parece existir a necessidade de trazer de volta algo que foi perdido em outro tempo, e esse algo pode vir a existir no espaço real das relações. Percebemos essa característica na obra de Kinceler, quando o artista afirma a necessidade de vislumbrarmos um outro tipo de arte, uma arte livre das regras da beleza e da estética convencional transmitidas ao longo da história da arte. Kinceler propõe a arte como acontecimentos que produzam sentidos na convivência.

Esse pensamento/ação que instala sua prática artística nos espaços das relações e não nos espaços simbólicos autônomos já estabelecidos, dirige seus esforços para gerar acontecimentos que produzam sentidos através da elaboração de estratégias de reinvenção do cotidiano. A estrutura de funcionamento é outra. Aqui não existe a obrigatoriedade da existência de um objeto artístico físico que represente algo ou que testemunhe a existência de um referente, o que interessa é provocar descontinuidades a partir de situações reais.

De certo modo, guardadas as devidas referências, a proposta da arte relacional em sua forma complexa7 apresenta uma proximidade com o que Favaretto nos relata sobre o que seria a experiência em Dewey. Experiência artística aqui aconteceria nas relações entre as pessoas e na produção de sentidos geradas a partir dessa aproximação.

Diante da massificação que vivemos, gerar acontecimentos que produzam sentidos é um desafio. De modo que os desvios, tanto da arte tradicional quanto do próprio cotidiano massificado, parece ser uma saída para a reinvenção da arte e da sociedade.

Ao propor uma forma de arte colada nas coisas da vida, a arte relacional em sua forma complexa atua no sistema da arte e no fluxo da vida. Não é pelo fato de se aproximar de situações reais e de propor acontecimentos na vida cotidiana que ela se desconecta do sistema de arte. Ao contrário, suas descontinuidades provocam uma diluição nos campos que foram convencionalmente separados.

Retomando Favaretto quando afirma que a experiência é um estar em relação, e a partir dessa relação deve-se produzir efeitos, em uma proposta de arte relacional, a descontinuidade deve acontecer amplamente, de modo que o participante também precisa ser de desestabilizado e ter seus conceitos revistos. Por isso a proposta deve ser aberta e não definida antecipadamente pelo artista que posteriormente vai expôr um resultado final de seu trabalho.

\footnotetext{
${ }^{7}$ O termo deriva das reflexões de Nicolas Borriaud, mas os desdobramentos práticos amplificam sobremaneira a teoria.
}

Revista Digital do LAV - Santa Maria - vol. 9, n. 3, p. 104 - 118 - set./dez. 2016 ISSN 1983 - 7348 http://dx.doi.org/10.5902/1983734824339 
São formas dinâmicas de atuação gerando descontinuidades que favorecem a reconstrução das subjetividades, a participação e os encontros a partir do convívio num espaço real.

Essa perspectiva denota uma forma de arte ligada a vida e de forte teor político. Muitos são os projetos artísticos que atuam nessa vertente. Atuando no Brasil podemos citar a dupla MALWAL- Mauricio Dias e Walter Riedweg ${ }^{8}$, artistas que questionam o sistema da arte e seus modos de circulação ao realizarem projetos artísticos de cunho político e educativo por meio de imersões na realidade. Um exemplo é o trabalho "Mera Vista Point" (2002, Brasil), composto por pequenos vídeos onde 33 camelôs que trabalham no Largo da Concórdia, em São Paulo tem um minuto para realizar um pequeno anúncio dos seus produtos. O trabalho imprimiu mudanças no funcionamento do comércio local e envolveu os vendedores na elaboração e exposição dos trabalhos.

Em Florianópolis, Santa Catarina, o artista professor José Luiz Kinceler realizou inúmeros projetos onde a sala de aula era transformada em laboratório de propostas relacionais. Assim como Beuys, ele acreditava que a arte poderia ser um modo de reinvenção do cotidiano, e afirmava que para ele "em arte não importa o objeto, mas as relações entre as pessoas".

O projeto que tive a oportunidade de participar enquanto aluna ${ }^{9}$ foi denominado por Panorâmica Mont Serrat. Mont Serrat é uma comunidade centralmente periférica da cidade Florianópolis, quando falamos comunidade, no Brasil, nos referimos a agrupamentos sociais marginalizados pelo desenvolvimento do capitalismo. O dispositivo que acionou a proposta foi a realização dos desejos.

A partir de uma atividade proposta pelo professor, cada participante expôs um desejo que pudesse ser realizado no coletivo, isso vinha de encontro ao que vínhamos discutindo desde o inicio do semestre.

Naquele semestre, como aluna especial, tínhamos a companhia da Rosa. Rosa é uma moradora do Mont Serrat, e nesta comunidade atua como professora. Seu desejo era ver o céu do Mont Serrat colorido. De modo que os desejos de todos se mesclaram ao desejo de Rosa na construção de uma plataforma em que todos estavam envolvidos na realização e organização de um trabalho coletivo, compartilhando responsabilidades num movimento em que os desejos individuais passavam a ser coletivos.

\footnotetext{
${ }^{8}$ Maurício de Mello Dias (Rio de Janeiro, Brasil, 1964) é formado em Artes Plásticas e Walter Stephan Riedweg (Lucerna, Suíça, 1955) é formado em Música e Teatro. Os dois se conheceram na Basileia, Suíça, em 1993, e trabalham juntos desde então.

${ }^{9}$ No programa de Pós-Graduação em Artes Visuais - UDESC, cursando a disciplina Arte Relacional nos Limites do Real, no ano de 2011.
} 
Através de ações que valorizam o espaço de (com)vivência, práticas criativas podem ajudar a criar espaços de descontinuidade e diluição dos campos de conhecimento onde um saber se mistura a outro (figuras 4 a 7 ).

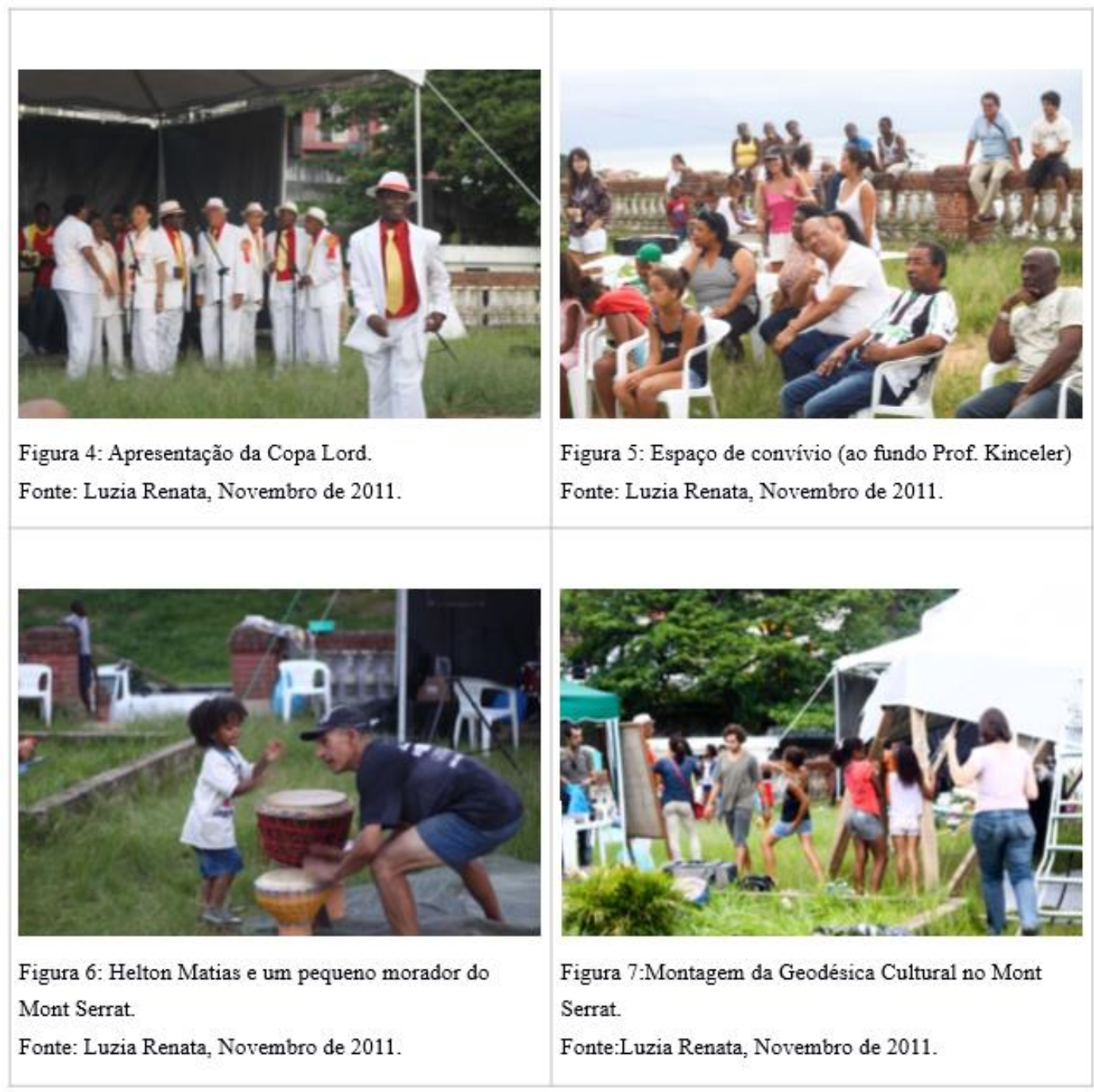

Aqui, a proposta se caracteriza por estabelecer várias tramas relacionais que provoquem sentidos na interseção de diferentes culturas, a descontinuidade deve existir dos dois lados.

\section{Considerações}

$\mathrm{Na}$ configuração desse texto, acreditamos poder traçar paralelos que nos ajudam encontrar não um rastro desde onde se pode descrever ou explicar a arte contemporânea, mas sim, alguns pontos de contato entre o espírito transformador da educação e da arte.

No texto "A educação do an-artista parte II" há uma passagem onde Allan Kapow

Revista Digital do LAV - Santa Maria - vol. 9, n. 3, p. 104 - 118 - set./dez. 2016 ISSN 1983 - 7348 http://dx.doi.org/10.5902/1983734824339 
aposta que a mudança social pode vir das escolas, e que mesmo com as regras burocráticas da escola, os professores acreditam poderem fazer a diferença. Isso corrobora em muito com a postura pedagógica de Joseph Beuys e também de José Kinceler. Ambos acreditavam poder mexer na estrutura da arte plantando uma ideia de arte misturada na vida, usando para isso seu ofício de artista professor.

Somente quando desejarem sessar de ser artistas, os artistas ativos podem converter suas habilidades, como dólares em yens, em algo que o mundo possa gastar: jogar-brincar. Jogar-brincar como moeda. Podemos aprender melhor a jogar-brincar mediante exemplos, e anartistas podem proporcionar isso. Em seu novo trabalho como educadores, eles precisam simplesmente jogar-brincar, como fizeram uma vez sob a bandeira da arte, mas em meio aqueles que não se importam com isso. Gradualmente o pedigree "arte" se retirará até tornar-se irrelevante (KAPROW, 2004, p. 181).

A arte colaborativa, a meu ver, pode ser pensada como um desdobramento dos pensamentos de Beuys e por consequência de Rudolf Steiner uma vez que propõe a construção de subjetividades que produzam sentidos, e ao fazê-lo questiona as formas de representação postas de antemão.

Quando nascemos fomos envolvidos em um contexto regrado por convenções humanas que se estabeleceram antes de nossa chegada. Mas há que se considerar que o ser humano vive em constante processo de transformação e habitando em um mundo mutante, de modo que inventar novas formas de arte, novas formas de educação e novas formas de olhar para mundo é uma condição humana que requer que alcancemos e compartilhemos os múltiplos saberes que cada um carrega em si.

\section{BIBLIOGRAFIA}

ABMA - Associação brasileira de medicina antroposófica. O ser humano segundo a Antroposofia. Acessado em: 21/12/2105. Disponível em:

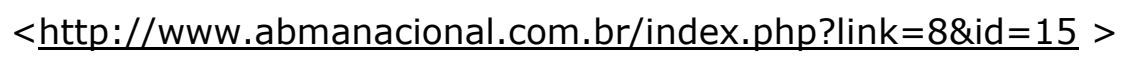

BENJAMIN, Walter. Reflexões sobre a criança, o brinquedo e a educação. São Paulo: Duas cidades/34, 2005.

. Magia e técnica, arte e política: ensaios sobre literatura e história da cultura. São

Revista Digital do LAV - Santa Maria - vol. 9, n. 3, p. 104 - 118 - set./dez. 2016 ISSN 1983 - 7348 http://dx.doi.org/10.5902/1983734824339 
Paulo,Brasiliense, 2012.

BORER, Alain. Joseph Beuys. São Paulo: Cosac \& Naify Edições, 2001.

CAMPBELL, Joseph. O poder do mito. São Paulo: Palas Athena, 1990.

FAVARETTO, Celso. John Dewey I: a relevância da experiência (1/2). Video da Univesp. Acessado em: 14/01/2016. Disponível em: < https://www.youtube.com/watch?v=-TcvEXvg1I>

KAPROW, Allan. A educação do An - Artista. Parte II. Concinnitas - Revista do Instituto de Artes da UERJ. Ano 5, n. 6, julho 2004, pp.167-181. Acessado em: 10/03/2015. Disponível em: www.concinnitas.uerj.br.

KINCELER, José Luiz. As noções de descontinuidade, empoderamento e encantamento no processo criativo de "vinho saber - arte Relacional em sua forma complexa". AMPAP, 2008. Acessado em: 12/01/2016. Disponível em: < http://anpap.org.br/anais/2008/artigos/162.pdf > .

LYNTON, Norbert. Futurismo. In: STANGOS, Nikos (org.). Conceitos da arte moderna. Rio de Janeiro: Jorge Zahar, 2000.

MARCONDES, Renan. Matéria em Constante Movimento: Joseph Beuys e Tim Ingold. Performatus. Ed. 14, Ano 03, no 14 Julho, 2015. Acessado em 12/01/2016. Disponível em < http://performatus.net/joseph-beuys-tim-ingold/>

STEINER, Rudolf. Abelhas: apicultura a partir do respeito pela vida. Tradução de Gerard Bannwart. Aracajú: Edições Micael, 2005.

.A arte da educação II: metodologia e didática. Tradução de Rudolf Lanz. São Paulo: Antroposófica, 2003.

VINCINI, Magda Salete. Dimensões comunicacionais no conceito de escultura social de Joseph Beuys: um processo de tradução criativa. Acessado em: 20/12/2015. Disponível em:

<file://C:/Users/luzia/Documents/lu\%20renata/Arquivos /UDESC/PROJETO\%20ESCRITA/b euys/Magda\%20Salete\%20Vicini\%20tese\%20escultura\%20social.pdf $>$. 


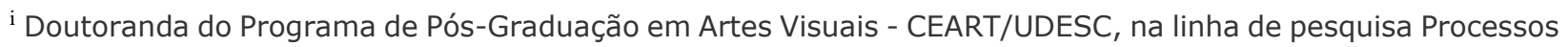
Artísticos contemporâneos e mestrado em Artes Visuais pela mesma instituição, oportunidade em que desenvolvi a pesquisa; Arthur Omar e a menina do brinco de pérola: anacronismos na fotografia contemporânea; defendido no ano de 2013 sob a orientação da pesquisadora Dra. Célia Maria Antonacci Ramos. Especialização em Fundamentos da Arte na Educação concluído na Faculdade de Artes do Paraná no ano de 2001, cuja pesquisa intitulou-se;Poéticas conceitual; tendo como orientadora a pesquisadora Ma. Daniela Vicentini. Paralelamente à produção acadêmica, desde o ano de 2003 me dedico a produção cultural, especificamente na área da fotografia. Atualmente coordeno o Festival de Fotografia Floripa na Foto, que acontece anualmente na cidade de Florianópolis e o núcleo de estudos em fotografia e arte - NEFA.

Enviado em: 10 de outubro de 2016.

Aprovado em: 22 de dezembro de 2016. 